\title{
Model of passenger rolling stock maintenance
}

\author{
Dmitry Bannikov ${ }^{1, *}$, and Nina Sirina ${ }^{1}$ \\ ${ }^{1}$ Ural State University of Railway Transport, 620034 Yekaterinburg, Russia
}

\begin{abstract}
In order to improve the quality of maintenance and repair of a passenger rolling stock, Russian Railways JSC requires transition to routine maintenance. The paper studies the main stages of building a discrete-event model of a passenger rolling stock maintenance using AnyLogic environment. The following key parameters of maintenance are used: maintenance facilities location, rolling stock operability index, probability index for operational efficiency (downtime and failure probability), maintenance and repair costs. The maintenance model is implemented in the integrated modeling library. Simulation model enables to implement the modeled system and obtain performance indicators of routine maintenance system operation. By simulating various conditions it is possible to evaluate efficiency of the studied maintenance system for a high-speed passenger rolling stock.
\end{abstract}

\section{Introduction}

Reorganization of Russian transportation system, particularly federal railways, caused significant changes in structure of transportation services. The number of transportation companies increased, including those with own rolling stock. Today, clients on the transportation market have higher demands in respect to the quality of transportation services [1].

Scientific support of maintenance system presently fails to provide accurate operational readiness assessments of a passenger rolling stock. There is lack of the ability to forecast the level of operational readiness considering the existing limits of finance, passenger flow, failure intensity $[2,3]$. The known methods are not integrated into a single complex model of maintenance system.

Time and financial parameters, as well as variation of maintenance and repair intensity are not fully accounted, hence, the obtained predictive estimates are incomplete. For optimization purpose, it is suggested to perform system modeling that includes simulation of routine maintenance of a passenger rolling stock. The built simulation model will represent a system that allows multiple implementation of various production scenarios, thus simplifying evaluation and forecasting of the maintenance system condition.

In [4], the model of maintenance planning is based on the probability of technical failures in a certain moment of time. The model is built of the following constituents: planning a facility, purchasing spare parts, defining the maintenance and repair intervals. The studies of Pierskalla and Voelker [5], Osaki and Nakagawa [6], Sherif and Smith [7],

\footnotetext{
* Corresponding author: bannikov_d@mail.ru
} 
Valdez-Flores and Feldman [8], Cho and Parlar [9] are focused on defining optimum maintenance resources and finding minimum economic life cycle. The authors distinguish traditional methods of problem solving by linear and dynamic programming, stochastic models and present value analysis.

Campbell [10] declares that there is no correct maintenance, but there are strategies that allow effective use of resources in certain situations. Anyway, organization of maintenance and repair shall be flexible.

Russian researchers pay a lot of attention to the use of mathematical methods for solving tasks of organization and management of rolling stock maintenance and repair. Wide application of statistical methods with the use of mathematical tools of queuing theory and theory of random processes for locating car-repair facilities on the railway network is described in the studies of V. Tsyganov, N. Sirina, M. Bolotin [11-13].

Scientific support of maintenance and repair management consists in development and application of routine maintenance model. This will facilitate transition from maintenance and repair of existing and high-speed passenger rolling stock to routine maintenance. The overall estimate of model implementation capacity enables to reasonably plan and organize maintenance and repair system. For that reason, development of routine maintenance model will provide accuracy of predictive estimates of operation and repair parameters which largely define the effectiveness of passenger rolling stock life cycle management.

\section{Modeling method}

Object of the developed simulation model is a passenger maintenance facility performing several functional operations on maintenance and repair of passenger rolling stock. Therefore, the model provides collection of statistical data on the following parameters:

- maintenance queuing time;

- average maintenance and repair time;

- distance between the operation location and maintenance facility;

- share of rolling stock serviced by the maintenance facility.

Simulation modeling of technological processes is based on the mathematical tool of the described process. Since the model is simplified and idealized during its development it is necessary to rationally define the level of assumptions in the described mathematical model. One of the accepted assumptions in the suggested model is distance between the operation location and maintenance facility. The distance is accepted as constant from the first scheduled repair of passenger rolling stock.

In general, maintenance and repair system [14-15] of passenger rolling stock is a queuing system. The flow of passenger cars subjected to maintenance and repair is complex and consists of two flows: 1 - the flow defined by failures in rolling stock; 2 - the flow of passenger cars assigned for maintenance and repair after the end of duration of time between repairs. The queuing theory provides analytical assessment and solution with system research limitations. The key data for describing queuing system operation are: flow of service applications, queue and output flow.

Building of the model was performed using system dynamics tools of the simulation model. This tool includes both discrete-event and agent-based modeling in AnyLogic environment. System dynamics is a simulation modeling approach, methods and tools of which allow understanding the structure and dynamics of the designed model. System dynamics is characterized by a high level of abstraction and can be used for strategic system modeling.

Discrete-event modeling presents the modeled system as a process, i.e. a sequence of operations performed with modeling agents. The model is graphically represented as a process diagram, with each block standing for a certain operation. 
Agent-based modeling is an alternative view of the modeled system behavior. Structure of the agent-based model can be described both graphically and with the preset scenario. The agent behavior can be preset by various actions upon occurrence of certain events.

Simulation model is the one that builds the trajectory of system condition variation. We can say that simulation model is a set of rules according to which the system passes from one state into another. These rules are set by means of differential equations and statecharts. Using output data of the model the system behavior can be analyzed within the set parameters.

\section{Model structure}

Let us consider the model of routine maintenance of rolling stock as a queuing system with the applications flow $\lambda$ (failure intensity) and service flow $\mu$ (repair intensity). System state graph is presented in Figure 1.

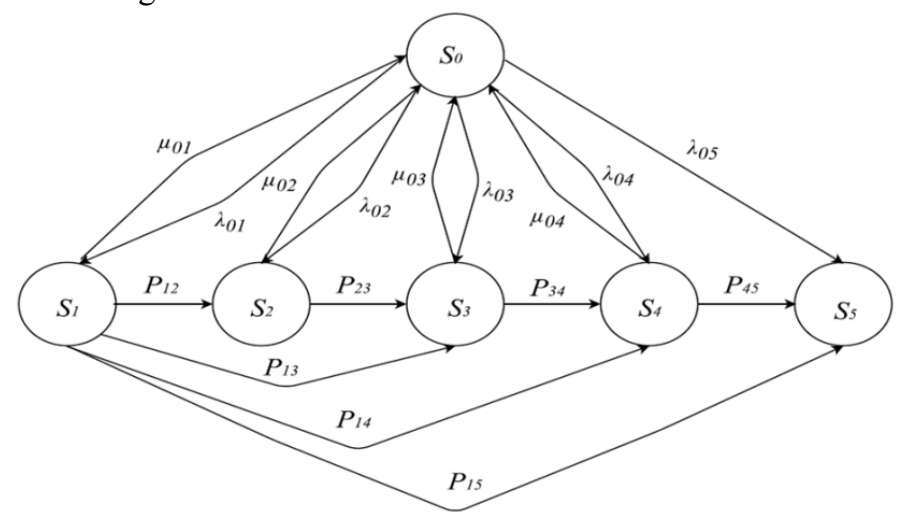

Fig. 1. Car state graph in a system.

Let us define the states in the graph as follows: $S_{0}$ - serviceable and in good operating condition; $S_{1}$ - out of service in operating condition; $S_{2}$ - out of service and nonoperable; $S_{3}$ - limit state retrievable after scheduled maintenance; $S_{4}$ - limit state retrievable after roundhouse servicing or overhaul repair; $S_{5}$ - ultimate limit state. $P i$ is the probability of car state transition. The state graph is described by the system of differential equations:

$$
\left\{\begin{array}{c}
\frac{d n_{0}(t)}{d t}=-\lambda_{01} n_{0}(t)+\mu_{10} n_{0}(t)-\lambda_{02} n_{0}(t)+\mu_{20} n_{2}(t)-\lambda_{03} n_{0}(t)+\mu_{30} n_{3}(t)- \\
-\lambda_{04} n_{0}(t)+\mu_{40} n_{4}(t)-\lambda_{05} n_{0}(t) ; n_{0}(0)=N_{0} \\
\frac{d n_{1}(t)}{d t}=\lambda_{01} n_{0}(t)-\mu_{10} n_{1}(t) ; n_{1}(0)=N_{1} \\
\frac{d n_{2}(t)}{d t}=\lambda_{02} n_{0}(t)-\mu_{20} n_{2}(t) ; n_{2}(0)=N_{2} \\
\frac{d n_{3}(t)}{d t}=\lambda_{03} n_{0}(t)-\mu_{30} n_{3}(t) ; n_{3}(0)=N_{3} \\
\frac{d n_{4}(t)}{d t}=\lambda_{04} n_{0}(t)-\mu_{40} n_{4}(t) ; n_{4}(0)=N_{4} \\
\frac{d n_{5}(t)}{d t}=\lambda_{05} n_{0}(t) ; n_{5}(0)=N_{5} \\
n_{0}(t)+n_{1}(t)+n_{2}(t)+n_{3}(t)+n_{4}(t)+n_{5}(t)=N(t)
\end{array}\right.
$$


Solution of the suggested system in AnyLogic environment includes the following stages. Solution of each stage depends on input data specified in the model. On the first stage of model building several classes of agents were introduced from the process modeling library, as well as statechart and elements of system dynamics of the agent. In this case the operating passenger rolling stock is taken as an agent. Simulation modeling of the maintenance system of passenger rolling stock cannot exist without creating algorithm for processing data and calculations. The second stage of building the model is a structured flow diagram of the model presented in Figure 2.

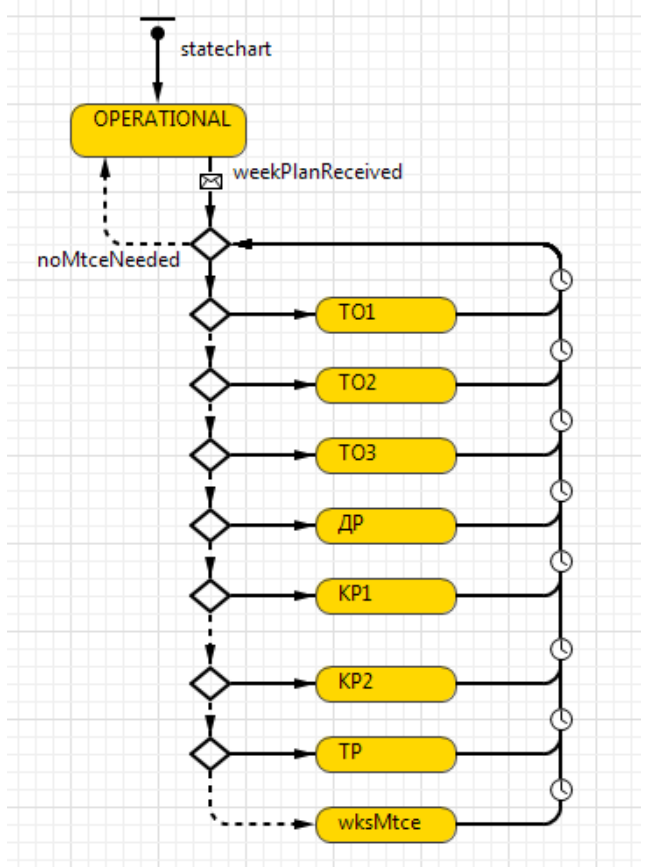

Fig. 2. Flow diagram of the maintenance model.

The built flow diagram represents a function of passing passenger rolling stock for maintenance and repair. The "Operational" statechart defines the agent behavior. The rolling stock is passed for maintenance after receiving the message «weekPlanReceived» which satisfies the set parameters. Then, branching and passage for required maintenance or repair occur. Each type of maintenance and repair is performed in certain period of time, after which the rolling stock will be serviced and put in operation.

The interface of the experiment "Planning of maintenance of passenger cars" (Fig. 3) includes elements of control and input of parameter values. The main parameters will be: car mileage, time between repairs, and the ability to change the downtime during maintenance depending on the rolling stock type. 


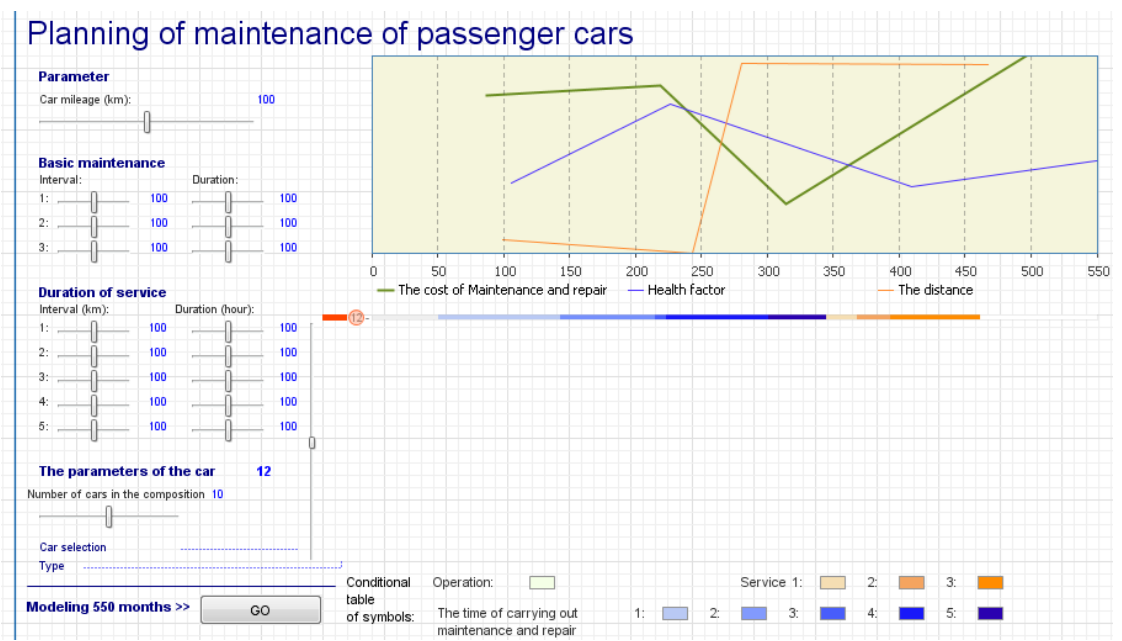

Fig. 3. Interface of the experiment "Planning of maintenance of passenger cars".

\section{Modeling results}

As a result of modeling the following data were obtained: an operability index variation graph (Fig. 4) for rolling stock, the level of costs for maintenance and repair, the average distance between the maintenance facility and the operation location of the rolling stock.

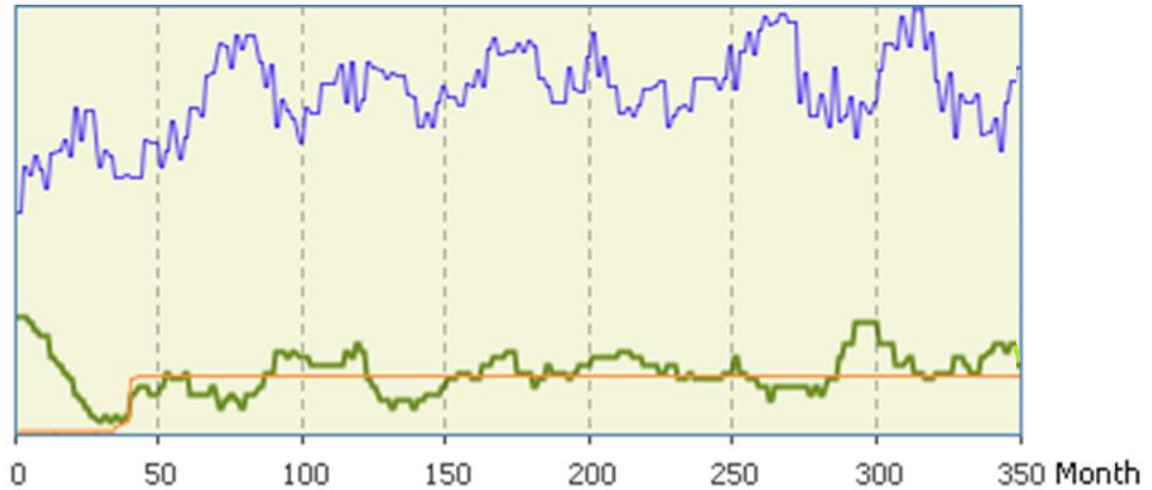

\section{- The cost of Maintenance and repair - Health factor - The distance}

Fig. 4. Modeling results.

Variation of operability index is defined by periodic pulse function of repair intensity $\mu$ of passenger rolling stock. Repair intensity depends on the type of performed maintenance or repair of rolling stock. In this model, repair intensity is constant and is characterized by the average repair time.

Maintenance and repair cost also depends on the type of performed maintenance and repair, and repair time. Besides, cost variation can be explained by the fact that the model accounts both scheduled types of passenger rolling stock repair and ordinary repair. Ordinary repair is accounted in the model at an arbitrary point of time defined by the function in the flow diagram of the system. 
The developed simulation model of passenger rolling stock maintenance enables to schedule and manage maintenance and repair along with the analysis of maintenance service development on the railway network. One can track the dynamics of variations in the modeling process by varying the input data of the model.

This simulation model will become the basis for maintenance optimization model. Optimization will allow defining the optimum location of maintenance facilities and finding the readiness index of passenger rolling stock for providing high-quality maintenance.

\section{Conclusion}

Variations occurring for different values can be compared by varying mileage between repairs and the duration parameter of maintenance and repair in the model. It is also possible to evaluate the impact of each parameter on the model behavior. The output of modeling is represented by the information required for developing predictive estimates of a system operation, which, in turn, influences managerial decision making.

Discrete-event modeling is an alternative method for modeling various processes in maintenance and repair of passenger rolling stock. When using all options of AnyLogic software the modeled situation can be implemented in its full range with demonstration of the model behavior and characteristics. This model is designed for defining optimum locations of maintenance facilities to provide high operational readiness index of passenger rolling stock and minimum time and financial expenditures for maintenance and repair.

The facilities will provide maintenance and repair services for passenger rolling stock. The services in the facilities are provided either by the passenger rolling stock manufacturer or by a private operating company upon agreement with the manufacturer. Such structure will provide stability of serviceable and good operating condition of rolling stock during the whole life cycle.

The developed model will be used as a foundation for building a simulation model of operating capacity of maintenance and repair facilities for passenger cars. The model will enable to forecast equal distribution of rolling stock among enterprises. For further development of the model, elaboration of the optimization model is suggested which will include statistical data of rolling stock failures. Based on these data, the possibility of downtime occurrence when expecting maintenance can be studied, as well as the impact on the operational readiness index and financial expenditures.

\section{References}

1. A. Rakhmangulov, A. Kolga, N. Osintsev, I. Stolpovskikh, A. Sladkowski, Transport Problems, Vol. 9, 125-132 (2014).

2. V.S. Timchenko, Vestnik transporta Povolzhya, Vol. 4, 59-66 (2017). (in Russian)

3. D.G. Evseev, K.G. Shcherbakov, Mir transporta [World of Transport and Transportation Journal], Vol. 3, 134-139 (2014). (in Russian)

4. A. Crespo Marquez, P. Moreu de Leon, J. Gomez Fernandez, C. Parra Marquez, V. Gonzalez, Safety, Reliability and Risk Analysis: Theory, Methods and Applications (Martorell et al. Taylor \& Francis Group, London2009).

5. W.J. Pierskalla, J.A. Voelker, Naval Research Logistics Quarterly, 23, 353-388 (1976).

6. S. Osaki, T. Nakagawa, IEEE Transactions on Reliability, 25, 284-287 (1976).

7. Y.S. Sherif, M.L. Smith, Naval Research Logistics Quarterly, 28, 47-74 (1981).

8. C. Valdez-Flores, R.M. Feldman, Naval Research Logistics, 36, 419-446 (1989).

9. D.I. Cho, M. Parlar, European Journal of Operational Research, 51, 1-23 (1991). 
10. J.D. Campbell, Uptime (Productivity Press, Portland, 1995).

11. N.F. Sirina, V.V. Tsyganov, Problema upravlenija [Management problems], 6, 93-95 (2006). (in Russian)

12. N.F. Sirina, Doctoral thesis, Ural State University of Railway Transport, Ekaterinburg, 2009. (in Russian)

13. M.M. Bolotin, Mir transporta [World of Transport and Transportation Journal], Vol. 3, 4-15 (2005). (in Russian)

14. Order of the Ministry of Railways of the Russian Federation No. 9, 04.04.1997 (ed. on 13.01.2011). Introduction of a new system of maintenance and repair of passenger cars (1997). (in Russian)

15. Normativnye sroki sluzhby mashin i oborudovanija [Normative service life of machines and equipment]. (in Russian) 